\title{
Epstein-Barr virus DNA load and its association with Helicobacter pylori infection in gastroduodenal diseases
}

\begin{abstract}
Helicobacter pylori and Epstein-Barr virus (EBV) infections are common worldwide. Although $H$. pylori infection is a major factor in gastroduodenal diseases, its role in association with EBV infection is unknown. Objective: To study the association of $H$. pylori infection and EBV DNA load in patients with gastroduodenal diseases. Methods: Biopsy samples were collected from 200 adult patients [non-ulcer dyspepsia (NUD) 100, peptic ulcer disease (PUD) 50, gastric carcinoma (GC) 50] undergoing upper gastrointestinal endoscopy. $H$. pylori infection was diagnosed by rapid urease test, culture, histopathology, PCR and Q-PCR. EBV DNA was detected by non-polymorphic Epstein-Barr nuclear antigen-1 (EBNA-1) gene based Q-PCR. Results: In patients with GC and PUD, EBV DNA was detected more often than NUD (GC versus NUD $=90 \%$ versus $37 \%, p<0.001$; PUD versus NUD $=70 \%$ versus $37 \%, \mathrm{p}<0.001$ ). The dual prevalence of $H$. pylori infection and EBV DNA was significantly higher in patients with GC and PUD than in those with NUD. Median copy number of EBV DNA was considerably higher in GC and PUD than NUD $(\mathrm{p}<0.01)$. The copy number of EBV DNA was significantly higher in $H$. pylori infected patients $(\mathrm{p}=0.015)$. The number of ureA gene copies was also found to be significantly higher in PUD and NUD with presence of EBV DNA. However, in GC no significant difference was seen between EBV positive and negative status. Conclusion: There was a trend for higher EBV DNA load in $H$. pylori positive individuals suggesting a probable role of $\mathrm{H}$. pylori in modulating the conversion of EBV to its lytic phase.
\end{abstract}

Keywords: Epstein-Barr virus infections; stomach neoplasms; Helicobacter pylori.

\section{INTRODUCTION}

Epstein-Barr virus (EBV), a ubiquitous herpes virus, infects approximately $95 \%$ of the world's population and is well documented to be causally associated with various malignant tumors, including Burkitt's lymphoma, nasopharyngeal carcinoma, and B-cell lymphoma in immunodeficient individuals, and is also proposed to play a causative role in gastric carcino$\mathrm{ma}$, as is $H$. pylori. ${ }^{1}$ The EBV genome in patients with gastric carcinoma (GC) varies in different geographical regions, e.g. Europe (8.75\%), Asia (7.99\%) and America (11.2\%). ${ }^{2}$ A higher prevalence of EBV associated GC was reported in the United States (16\%) where GC risk is one of the lowest in the world. Countries like India (33.3\%), Poland (28\%), and Turkey (50.2\%) also have a higher prevalence of EBV in GC patients..$^{2-5}$ Based on these findings, it is argued that the areas with a low incidence of GC have a relatively high proportion of EBV in patients with GC. ${ }^{2}$ However, when meta-analysis was restricted to studies that used EBER-in situ hybridization (ISH) for EBV detection in gastric carcinoma, no appreciable difference was seen in geographical prevalence rates and suggested that geographical differences are actually just differences in the methods of EBV detection. ${ }^{6}$ So, the methods used to detect the EBV DNA or EBV infection may potentially give rise to variations in the virus detection rate within different tissues and disease groups. Nowadays, newer detection methods such as PCR and real-time PCR (Q-PCR) have also revolutionized the clinical microbiology laboratories to diagnose human pathogens even when they are present in small number of copies. ${ }^{7}$ Advantages over EBER-ISH are PCR's relatively low cost, its applicability to specimens with poor-quality RNA, and its ability to detect (pure lytic) infection lacking EBER transcripts. ${ }^{8}$
Authors

Sanket Kumar Shukla

K.N. Prasad ${ }^{2}$

Aparna Tripathi ${ }^{1}$

Avinash Singh ${ }^{1}$

Ashish Saxena $^{3}$

Uday Chand Ghoshal ${ }^{4}$

Narendra Krishnani ${ }^{5}$

Nuzhat Husain ${ }^{2}$

${ }^{1} \mathrm{PhD}$ Students, Department of Microbiology, Sanjay

Gandhi Postgraduate

Institute of Medical

Sciences, India

${ }^{2} \mathrm{MD}$, Professors,

Department of

Microbiology, Sanjay

Gandhi Postgraduate

Institute of Medical

Sciences; Department of

Pathology, Ram Manohar

Lohia Institute of Medical

Sciences, India

${ }^{3} \mathrm{PhD}$, Post-doc

Fellow, Department

of Biochemistry and

Molecular Biology,

University of Texas Medical

Branch, USA

${ }^{4} \mathrm{DM}$, Associate

Professor, Department of

Gastroenterology, Sanjay

Gandhi Postgraduate

Institute of Medical

Sciences, India

${ }^{5} \mathrm{MD}$, Additional Professor,

Department of Pathology,

Sanjay Gandhi Postgraduate

Institute of Medical

Sciences, India

Submitted on: 06/02/2011 Approved on: 07/28/2011

Correspondence to:

Kashi N. Prasad

Department of

Microbiology

Sanjay Gandhi

Postgraduate Institute of

Medical Sciences

Lucknow-226 014, India

Phone: 91-522-2668631

Fax: 91-522-2668017

knprasad@sgpgi.ac.in

We declare no conflict of interest. 
Some authors also found increased rate of EBV infection in GC patients by using this technique. ${ }^{9-11}$ The association of EBV with peptic ulcer disease (PUD), another important gastroduodenal disease, has not been clearly defined. However, some authors also reported EBV infection in preneoplastic gastric lesion, and gastritis regions. ${ }^{12-14}$

EBV can infect the cell in either latent or a lytic manner. During the latent phase of the EBV viral life cycle, there is no production of infectious viruses and a highly restricted number of latent infection genes are expressed. Infectious viruses are produced during the lytic phase of EBV life cycle. Approximately 80 viral proteins are expressed during lytic viral replication, including transcriptional activators, DNA replication factors, and structural proteins such as viral capsid antigens. ${ }^{15}$ These events further increase the viral load of EBV. Recently it was reported in one study that $H$. pylori associated $\mathrm{NH}_{2} \mathrm{Cl}$ induces EBV lytic infection from latent infection in gastric epithelium latently infected with EBV. ${ }^{16}$ Thus, it is of interest to determine whether $H$. pylori infection can affect the viral load of EBV in GC and PUD patients. So, in this study our aim was, firstly, to determine the EBV viral load in patients with GC and PUD; and, secondly, to correlate the EBV viral load to $H$. pylori infection.

\section{METHODS}

\section{Patient population}

We enrolled 200 adult patients [non-ulcer dyspepsia (NUD) 100, PUD 50, GC 50] undergoing upper gastrointestinal endoscopies at Sanjay Gandhi Postgraduate Institute of Medical Sciences, Lucknow, between November 2005 to August 2009. The diagnosis of gastroduodenal diseases was based on clinical, endoscopic and histopathologic examinations. Patients with NUD were considered as controls in our study. The ethics committee of the institute granted approval for the study and all the patients gave their consent to participate. Subjects who had received antimicrobial therapy, $\mathrm{H}_{2}$-receptor blockers, proton-pump inhibitors and non-steroidal anti-inflammatory drugs 30 days prior to endoscopy were excluded from the study.

\section{Detection of EBV DNA}

For EBV detection, gastric biopsies were collected from cancer as well as ulcer region of GC and PUD patients. Biopsies were also taken from the normal region of the stomach. Further DNA was extracted from these tissues with the QIAamp DNA mini kit (QIAGEN, Hilden, Germany). Q PCR was performed by targeting the nonpolymorphic Epstein-Barr nuclear antigen-1 (EBNA-1) gene using Corbett Research 6000 Q-PCR instrument and Rotor gene 6000 software. Primer sequences, probe and thermocycling conditions were taken from a previous work. ${ }^{8}$ Each $25 \mu \mathrm{L}$ reaction contained $1 \mathrm{x}$ TaqMan Universal Master Mix, forward and reverse primer (15 pmol each), and TaqMan probe (10 pmol). DNA volume was $5 \mu \mathrm{L}(1 \mu \mathrm{g})$ for gastric tissues. To check for amplicon contamination, every run contained at least two "no template" controls in which nuclease free $\mathrm{H}_{2} \mathrm{O}$ was used instead of the template. The reporter dye (FAM) signal was measured against the internal reference dye (ROX) signal to normalize the signals for non-PCR-related fluorescence fluctuations that occur from well to well.

\section{Detection of $H$. pylori infection}

During each endoscopic examination, antral biopsies from normal region of antrum were obtained and subjected to the following tests: rapid urease test (RUT), culture, histopathology and $H$. pylori-specific ureA polymerase chain reaction (PCR) following the standard protocol as previously described. ${ }^{17} \mathrm{~A}$ Q-PCR assay was also performed targeting ureA gene of $H$. pylori by using Corbett Research 6000 instrument and Rotor gene 6000 software. The sequence of primer, probe and thermo cycling conditions were taken from previous published literature. ${ }^{18} H$. pylori infection was diagnosed if culture was positive or when at least two out of four other tests (RUT, histopathology, PCR and Q- PCR) were positive.

\section{Construction of standards and calculation of copy number of EBV and ure A gene of $H$. pylori}

For quantitation of the number of EBV copies, a standard curve was generated using 10-fold dilutions of bacterial plasmid DNA containing EBNA-1 sequence of EBV (kindly provided by University of WisconsinMadison), varying from $10^{10}$ to $10^{1}$ copies of EBV DNA, and for detection of the number of ureA copies of $H$. pylori, 10-fold dilutions of DNA extracted from the $H$. pylori type strain (ATCC 26695), varying from $10^{5}$ to $10^{1}$ copies. Both these curves were considered acceptable if a difference of $3.3 \pm 0.3$ cycles was demonstrated between each of the 10-fold dilutions, and if the correlation coefficient was at least 0.99 . A commercially available Q-PCR assay targeting human GAPDH gene was used (Genome diagnostic Pvt. Ltd. India) to control the efficacy of DNA extraction and to normalize the number of cells amplified per reaction. EBV viral load and copy number of ureA gene in tissue were calculated based on the following formula: (number of EBV or ureA copies) / [(number of human GAPDH copies)/2]. The resulting ratio was then multiplied by 100,000 to provide the number of copies of EBV and ureA gene per 100,000 cells. Quantification results for experimental samples were extrapolated from the standard curve. Experimental samples were run in duplicate and a median viral load was calculated. 


\section{Histopathology}

Sections of $5 \mu \mathrm{m}$ were cut from formalin fixed biopsy, embedded in paraffin. The sections were stained with hematoxylin and eosin for light microscopy for the presence of $H$. pylori infection. Patients with GC were confirmed by histopathology and classified into intestinal, diffuse and mixed according to the Lauren classification. ${ }^{19}$

\section{Statistical analysis}

Data were analyzed using SPSS software (version 12.0, SPSS, Chicago, IL., USA). H. pylori and EBV status in relation to gastroduodenal diseases and histological types of GC was assessed by Chi square test. The number of copies of EBV DNA and ureA gene of H. pylori were compared with the Mann-Whitney rank sum test. All the p-values were two sided and considered significant when less than 0.05 .

\section{RESULTS}

\section{Patient characteristics}

Demographic parameters of the 200 patients enrolled in the study are presented in Table 1.

\section{Detection of $\boldsymbol{H}$. pylori infection}

H. pylori infection was significantly higher in patients with PUD than in those with GC $(\mathrm{p}=0.044)$ and NUD ( $p<0.001$ ); however, no difference was observed between GC and NUD ( $\mathrm{p}=0.083)$ (Table 2). The median ureA copy of $H$. pylori in PUD was significantly higher than GC [PUD versus GC, 3887 (interquartile range 428 to 26327 ) versus 2100 (interquartile range 225 to 3428.95 ); $\mathrm{p}=0.028)]$. The median copy number of ureA was also higher in NUD, when compared to GC, but we could not reach at significant level [NUD versus GC 3724

Table 1. Demographic characteristics of patients included in the study

\begin{tabular}{lcccc}
\hline Parameters & $\begin{array}{c}\text { Non-ulcer } \\
\text { dyspepsia }(\mathbf{n}=\mathbf{1 0 0})\end{array}$ & $\begin{array}{c}\text { Peptic ulcer } \\
\text { disease }(\mathbf{n}=\mathbf{5 0})\end{array}$ & $\begin{array}{c}\text { Gastric) } \\
\text { carcinoma }(\mathbf{n}=\mathbf{5 0})\end{array}$ & Total (200) \\
\hline $\begin{array}{l}\text { Mean age } \pm \text { SD } \\
\text { (years) }\end{array}$ & $43.86 \pm 14.576$ & $48.08 \pm 16.491$ & $52.43 \pm 12.378$ & $55.72 \pm 13.837$ \\
\hline Male & $62(62 \%)$ & $34(68 \%)$ & $36(72 \%)$ & $132(66 \%)$ \\
\hline Female & $38(38 \%)$ & $16(32 \%)$ & $14(28 \%)$ & $68(34 \%)$ \\
\hline
\end{tabular}

Table 2. Presence of Helicobacter pylori, Epstein-Barr virus (EBV) and dual agents (H. pylori and EBV DNA) in patients with gastroduodenal diseases

\begin{tabular}{|c|c|c|c|c|c|c|}
\hline \multirow[t]{2}{*}{ Disease } & \multicolumn{2}{|c|}{ H. pylori infection* } & \multicolumn{2}{|c|}{ EBV DNA $* *$} & \multicolumn{2}{|c|}{$\begin{array}{c}\text { Dual agent } * * * \\
\text { (H. pylori and EBV DNA) }\end{array}$} \\
\hline & + & - & + & - & + & - \\
\hline $\begin{array}{l}\text { NUD } \\
(\mathrm{n}=100)\end{array}$ & $\begin{array}{c}46 / 100 \\
(46)\end{array}$ & $\begin{array}{l}54 / 100 \\
(54)\end{array}$ & $\begin{array}{l}37 / 100 \\
(37)\end{array}$ & $\begin{array}{l}63 / 100 \\
(63)\end{array}$ & $\begin{array}{l}23 / 100 \\
(23)\end{array}$ & $\begin{array}{l}77 / 100 \\
(77)\end{array}$ \\
\hline $\begin{array}{l}\text { PUD } \\
(\mathrm{n}=50)\end{array}$ & $\begin{array}{c}41 / 50 \\
(82)\end{array}$ & $\begin{array}{l}9 / 50 \\
(18)\end{array}$ & $\begin{array}{l}35 / 50 \\
(70)\end{array}$ & $\begin{array}{l}15 / 50 \\
(30)\end{array}$ & $\begin{array}{c}31 / 50 \\
(62)\end{array}$ & $\begin{array}{l}9 / 50 \\
(38)\end{array}$ \\
\hline $\begin{array}{l}\text { GC } \\
(n=50)\end{array}$ & $\begin{array}{c}31 / 50 \\
(62)\end{array}$ & $\begin{array}{c}19 / 50 \\
(38)\end{array}$ & $\begin{array}{c}45 / 50 \\
(90)\end{array}$ & $\begin{array}{l}5 / 50 \\
(10)\end{array}$ & $\begin{array}{l}27 / 50 \\
(54)\end{array}$ & $\begin{array}{c}23 / 50 \\
(46)\end{array}$ \\
\hline $\begin{array}{l}\text { Total } \\
(\mathrm{n}=200)\end{array}$ & $\begin{array}{c}118 / 200 \\
(59)\end{array}$ & $\begin{array}{l}82 / 200 \\
(41)\end{array}$ & $\begin{array}{l}113 / 200 \\
(56.5)\end{array}$ & $\begin{array}{c}87 / 200 \\
(43.5)\end{array}$ & $\begin{array}{c}81 / 200 \\
(40.5)\end{array}$ & $\begin{array}{l}119 / 200 \\
(59.5)\end{array}$ \\
\hline
\end{tabular}

H. pylori infection*, PUD versus NUD: (82\% versus 46\%, $\mathrm{p}<0.001)$; GC versus NUD: (62\% versus $46 \%, \mathrm{p}=0.083)$; PUD versus GC: (82\% versus $62 \%, \mathrm{p}=0.044)$;

EBV DNA**, PUD versus NUD: (70\% versus 37\%, p < 0.001); GC versus NUD: (90\% versus 37\%, p < 0.001); GC versus PUD: (90\% versus $70 \%, \mathrm{p}=0.023)$;

Dual agents (H. pylori and EBV DNA)**** PUD versus NUD: (62\% versus 23\%, p < 0.001); GC versus NUD: (54\% versus 23\%, $\mathrm{p}<0.001)$ 
(interquartile range 672.31 to 20500) versus 2100 (interquartile range 225 to 3428.95$)(\mathrm{p}=0.074)$ ] (Figure 1A).

\section{Detection of EBV DNA}

The detection of EBV DNA was based on amplification of the non-polymorphic Epstein-Barr nuclear antigen-1 (EBNA-1) gene by Q-PCR. The frequency of EBV DNA in our study population was $56.5 \%$. A significantly higher number of patients with GC and PUD had EBV DNA in comparison with patients with NUD $(\mathrm{p}<0.001)$. The EBV infection rate was also found to be significantly higher in GC patients when compared to PUD ( $p=0.023)$ (Table 2). The median copy number of EBV DNA in our population was 449.80 . The median copy number in GC and PUD patients was found to be significantly higher when compared to NUD [GC versus NUD, 1329.18 (interquartile range 158 to 5601 ) versus 86.79 (interquartile range 36.34 to 386.74 ); $\mathrm{p}<0.001$ and PUD versus NUD 754.00 (interquartile range 290 to 2324 ) versus 86.79 ; $\mathrm{p}<0.001]$. However no difference was found between GC and PUD $(\mathrm{p}=0.636)$ (Figure $2 \mathrm{~A})$. Data were also analyzed between normal and cancer/ulcer tissue. Out of 50 GC patients, none of them presented a detectable copy number of EBV DNA in normal mucosa. However out of 50 PUD patients, 7 (14\%) had detectable EBV DNA in their normal mucosa. The median copy number of EBV DNA was significantly higher in ulcer tissue when compared to normal mucosa [ulcer versus normal tissue 1759 (interquartile range 367.50 to 5854) versus 95 (interquartile range 27.75 to 462.50 ); $\mathrm{p}=0.01$ ] (Figure $2 \mathrm{C}$ ).
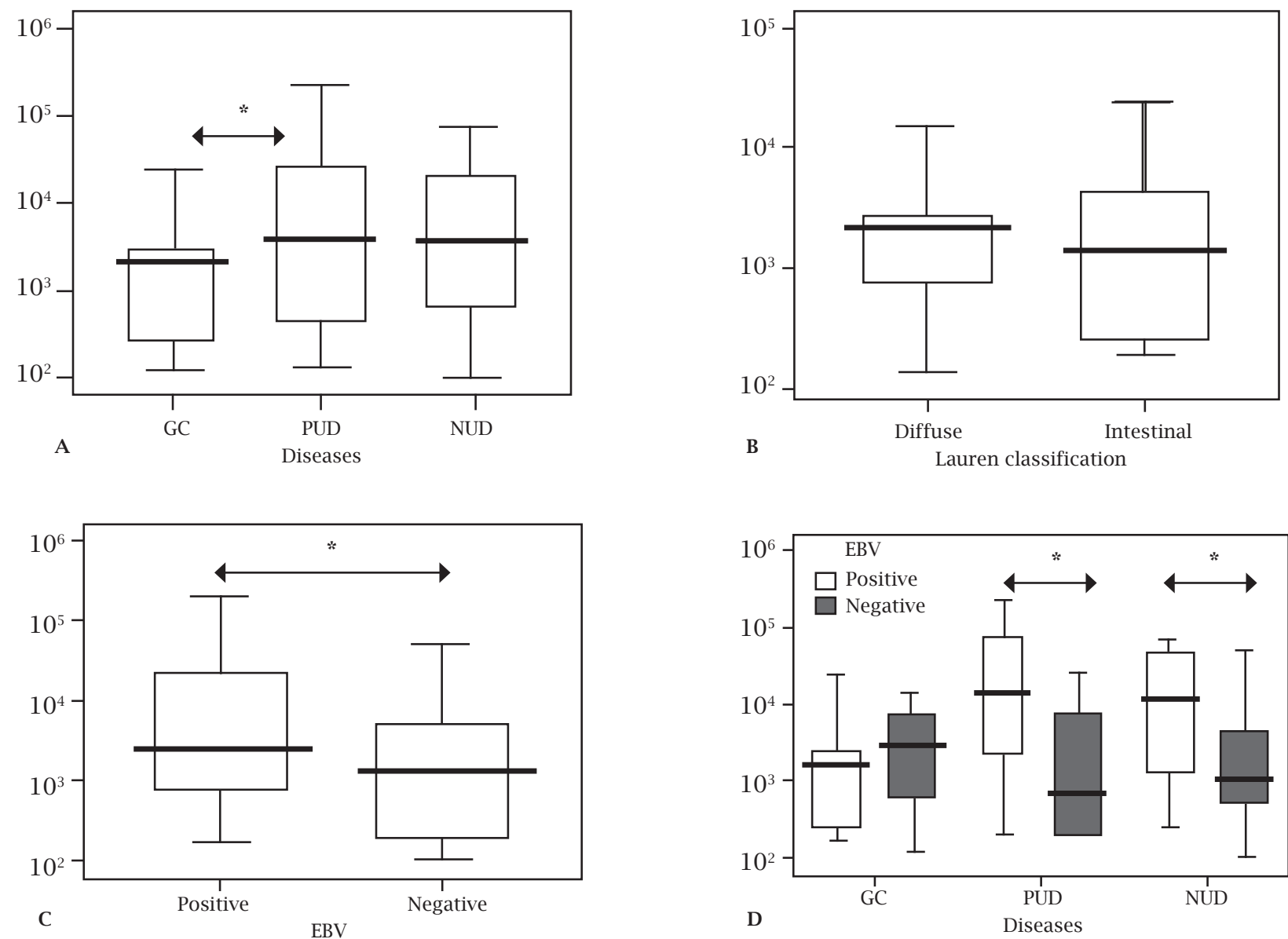

$* \mathrm{p}<0.05$

Figure 1: Calculation of ureA gene copy number of $H$. pylori (per 1000,000 cells). (A) shows the median copy number of ureA in GC, PUD and NUD. The copy number was compared between GC and PUD ( $p=0.028)$, PUD and NUD ( $p=0.507)$ and GC and NUD ( $p=0.074)$. (B) shows the comparison of ureA copy number between EBV infected and non infected patients ( $p=0.006)$. (C) shows the comparison of ureA copy number in ulcer and normal tissue of same patients $(p=0.01)$ and (D) shows the disease wise difference in copy number of ureA in presence and absence of EBV. In each panel, the lines inside the boxes denote the medians, the boxes denote the interquartile ranges, and the I bars indicate the $10^{\text {th }}$ and $90^{\text {th }}$ percentiles. 

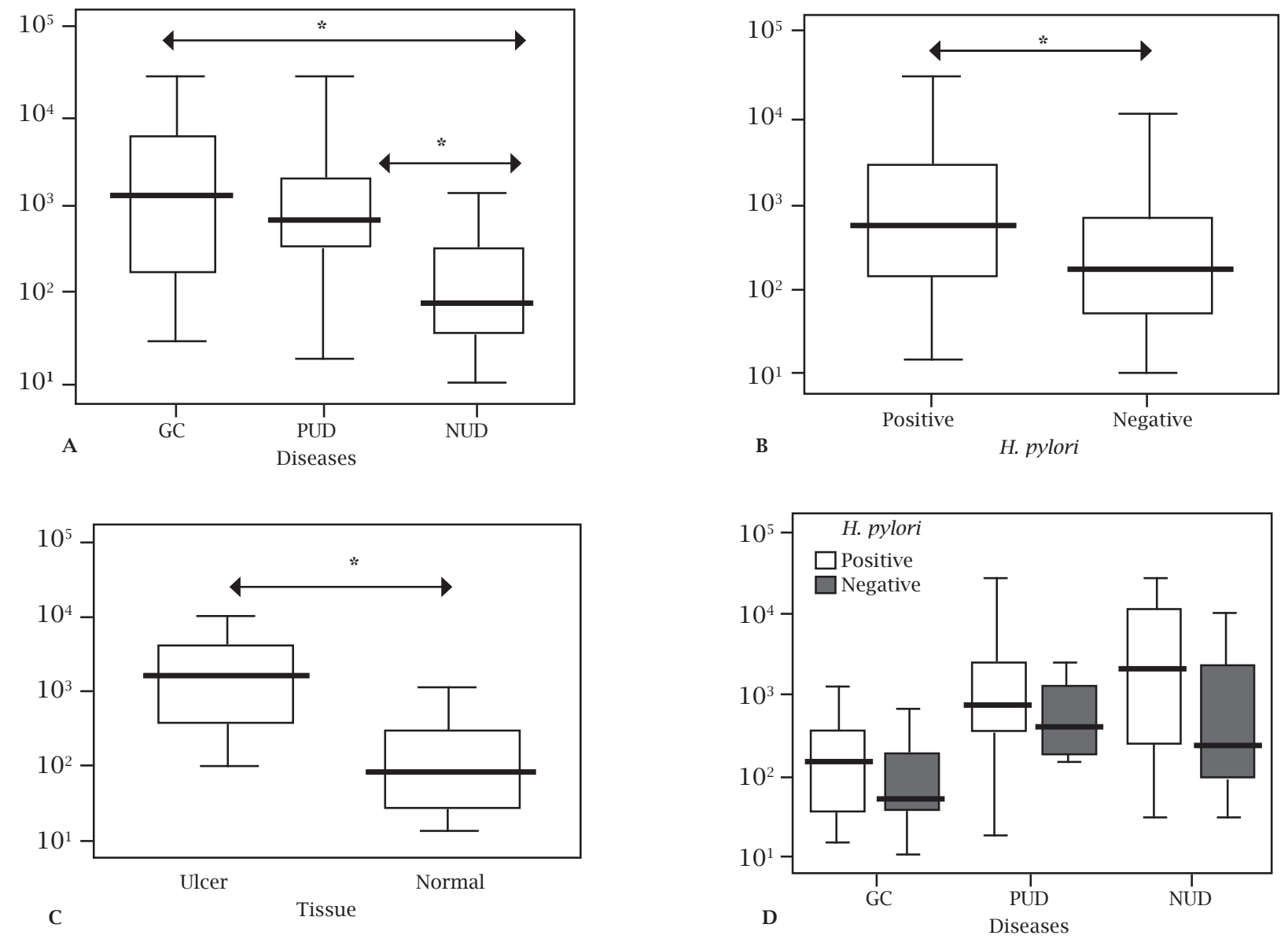

Figure 2: Calculation of median copy number of EBV DNA (per 1000,000 cells). (A) shows the median copy number of EBV DNA in GC, PUD and NUD patients. The copy number was compared between GC and PUD $(p=0.001)$, PUD and NUD ( $p=0.001)$ and GC and NUD ( $p=0.636)$. (B) shows difference in median copy number of EBV DNA in $H$. pylori positive and negative patients $(p=0.015 *)$. (C) shows the difference in median copy number of EBV DNA in ulcer and normal tissue $(p=0.01)$ and $(\mathrm{D})$ shows the disease wise difference in EBV DNA in presence and absence of $H$. pylori. In each panel, the lines inside the boxes denote the medians, the boxes denote the interquartile ranges, and the I bars indicate the $10^{\text {th }}$ and $90^{\text {th }}$ percentiles.

\section{Measurement of EBV viral load and its relation to H. pylori infection}

The dual infection by $H$. pylori and EBV was significantly higher in patients with GC and PUD than in those with NUD $(\mathrm{p}<0.001)$. The overall dual prevalence of $H$. pylori infection and EBV DNA in our study population was $40.5 \%$. H. pylori infection alone was not significantly related to GC but the presence of $H$. pylori infection and EBV DNA was associated with both GC and PUD (Table 2). In overall study population, the median copy number of EBV DNA in $H$. pylori infected patients was significantly higher than uninfected patients $[H$. pylori positive v/s H. pylori negative patients, 519.35 (interquartile range 151 to 2544 ) versus 177.80 (interquartile range 49.99 to 697.60 ); $\mathrm{p}=0.015$ ] (Figure 2B). However, no difference was observed when the data were analyzed in individual disease group between $H$. pylori infected versus non-infected patients (Figure 2C).
In overall study population the median copy number of ureA gene of $H$. pylori was significantly higher in EBV positive patients when compared to the EBV negative patients [EBV positive versus EBV negative, 2500 versus 1329 $(p=0.006)]$ (Figure 1C). Same observation was also seen (except GC) when data analyzed in individual disease group between EBV infected and non-infected patients (Figure 1D).

\section{Histological findings in patients with GC and measurement of EBV viral load}

Patients with GC were confirmed by histopathology and classified into intestinal, diffuse and mixed type according to the Lauren classification. The distribution of different types of GC was as follows: intestinal type 24 (48\%), diffuse type 26 (52\%). None of our patients had mixed type of adenocarcinoma. Detection of EBV genome was almost in equal proportion in both the diffuse $(92.3 \%)$ and the 
intestinal (87.5\%) GC types. The prevalence of $H$. pylori infection and EBV DNA tended to be somewhat similar in intestinal (58.3\%) and in diffuse type (53.8\%) of GC with no significant difference. The median copy number of EBV DNA and ureA was also similar in both diffuse as well as intestinal type of carcinoma with no significant difference. EBV DNA: [intestinal versus diffuse; 690 (interquartile range 169.85 to 2541.81) versus 2373.4190 (interquartile range 150.35 to 9675$)(\mathrm{p}=0.382)]$. ureA: [intestinal versus diffuse; 1544 (interquartile range 210 to 4242.40 ) versus 2100 (interquartile range 450 to 2500$)(\mathrm{p}=0.790)]$ (Figure 1B).

\section{DISCUSSION}

The aim of present study was to compare the EBV DNA load with $H$. pylori infection in patients with GC and PUD. A significantly higher number of patients with GC (90\%) and PUD (70\%) had EBV DNA when compared to NUD (37\%). The EBV DNA load was also found to be significantly higher in these disease groups. However, we did not found any EBV DNA in normal tissue of GC patients. Previous studies also did not found any EBV DNA in preneoplastic or normal mucosa of GC patients and suggested that EBV infection of gastric epithelial cells is not an early event in gastric carcinogenesis. ${ }^{11,20}$ However, in PUD, a significantly lower copy number of EBV DNA was detected in normal tissue when compared to ulcer tissue. To the best of our knowledge this is the first study which compared the EBV DNA load both in normal as well as ulcer tissue in PUD patients. The paucity of data in the world literature did not allow comparison of our figures with other studies addressing the prevalence and load of EBV DNA in patients with NUD and PUD. However, few studies also reported EBV DNA in normal gastric mucosa other than GC and concluded that the gastric epithelium is frequently infected with EBV and prolonged EBV persistence may contribute to the development of gastric carcinogenesis. ${ }^{12-14}$

EBER-ISH is the gold standard for EBV detection in biopsy specimen. ${ }^{7}$ However, the sensitivity of EBER staining has been called into question by investigators who have shown, by molecular or immunohistochemical assays, that EBV is present in some EBER-negative tumors. ${ }^{21-23}$ The sensitivity of this assay also depends on the viral load and sensitivity of assay decreases when virus is present in low copy number. ${ }^{11}$ Recently in America, EBV DNA was detected by Q-PCR in 64\% of United States and in 100\% Central America GC which are concordant with our current finding. This study also concluded that the Q-PCR amplification technology is better than EBER-ISH for identifying cases of GC that are EBV related. ${ }^{24}$ We also analyzed the load of EBV DNA in two histological types of GC. No difference in the presence of EBV DNA was observed in our GC patients with either diffuse (92.3\%) or intestinal type (87.5\%). The data are concordant with the earlier studies on GC. ${ }^{25,26}$ Although the median concentration of EBV was higher in diffuse type than intestinal type, but we could not reach at significant level.

Currently, only a few studies have investigated the interaction of EBV and H. pylori infection in GC, but they did not found any association of these two pathogens. ${ }^{9,27,28}$ However, few studies reported that chronic atrophic gastritis and subsequent intestinal metaplasia caused by $H$. pylori infection enhances the susceptibility of EBV to gastric mucosal epithelia, and then EBV facilitated the carcinogenesis of gastric carcinoma. ${ }^{13-14}$ Recently, it was reported in one study that H. pylori associated $\mathrm{NH}_{2} \mathrm{Cl}$ induces $\mathrm{EBV}$ lytic phase conversion in gastric epithelium latently infected with EBV. ${ }^{16}$ In our study, we simultaneously detected the status of $H$. pylori infection and the load of EBV DNA in patients with GC and PUD. Further we also compared the copy number of ureA gene of $H$. pylori in EBV infected and non infected patients. Ethically, healthy individuals without upper gastrointestinal symptoms should not be subjected to endoscopies, hence patients with NUD undergoing endoscopies were considered as controls. H. pylori infection rate in our study population was higher (59\%) than earlier report (53.4\%). ${ }^{29}$ This is most likely due to the use of Q-PCR in the present study. The prevalence of $H$. pylori in GC reported in our study was low, as was reported by Sipponen et al., ${ }^{30}$ but similar to other studies. ${ }^{31-33}$ Other studies from India also failed to show an association between $H$. pylori infection and GC. ${ }^{34-36}$ The chances of finding $H$. pylori in the biopsy specimens become less likely when the changes in chronic atrophic gastritis and intestinal metaplasia set in the stomach. These changes lead to absence of or a decrease in the H. pylori load in the stomach, probably due to the lack of nutrients for this organism. ${ }^{37}$ In addition, bacteria may be hidden within the mucosal cells and without producing urease in the lumen. ${ }^{38}$ So, these may be the probable reasons for the low prevalence as well as lower copy number ureA gene of $H$. pylori infection when a tissue based diagnosis is made in GC patients.

The dual prevalence of $H$. pylori infection and EBV DNA was significantly higher in patients with GC (54\%) and PUD (62\%) than in those with NUD (23\%). Interestingly, we found that the presence of $H$. pylori infection and EBV DNA was associated with both GC and PUD. So, it is hypothesized that interaction between $H$. pylori and EBV may have some synergistic mechanism in the pathogenesis of the disease.

In our study the copy number of EBV DNA was significantly higher in $H$. pylori infected patients than uninfected patients. But we could not found significant association of $H$. pylori with copy number of EBV DNA in individual patient group. However, in contrast to these findings copy number of ureA gene was significantly associated with EBV infection in PUD and NUD.

We found increment of EBV DNA load in H. pylori infected patients, which somehow supported our current hypothesis. However, it is unclear that this increment was due to the reactivation of EBV. An alternative explanation 
for higher EBV viral loads in diseased tissue could be a simple increase in the number of EBV positive cells rather than amplification of virus itself through lytic replication. Another thought might be that what if NUD somehow prevents EBV infection? Because this is a preliminary study, it is necessary to further explore EBV reactivation and some host factors to reach any conclusion. Moreover, virulence properties of $H$. pylori other than the urease are also required to know the exact interactions between H. pylori and EBV.

In conclusion, the trend of EBV DNA load was higher in $H$. pylori positive individuals suggesting the probable role of $H$. pylori in modulating the conversion of EBV to its lytic phase. Hence, there is a need to explore latent and lytic phase of EBV in relation to $H$. pylori infection and other factors, if any. However, further studies on larger patient populations are also required to know the exact interactions between the two most common gastric pathogens.

\section{ACKNOWLEDGEMENTS}

The study was supported by the research fund of Sanjay Gandhi Postgraduate Institute of Medical Sciences, Lucknow, India (PGI/IMP/EC/48/2009). We thank to Dr. Bill Sougden of the University of WisconsinMadison for generous gift of bacterial plasmid DNA containing EBNA-1 fragment. Sanket Shukla gratefully acknowledges the Department of Biotechnology, Government of India (DBT), New Delhi, for a senior research fellowship through grant no. (DBT-JRF)/09-10/634.

\section{REFERENCES}

1. Rickinson AB, Kieff E. Fields Virology: Philadelphia, Lippincott Williams \& Wilkins 2001.

2. Sousa H, Pinto-Correia AL, Medeiros R, et al. Epstein-Barr virus is associated with gastric carcinoma: the question is what is the significance? World J Gastroenterol. 2008; 14:4347-51.

3. Shibata D, Weiss LM. Epstein-Barr virus-associated gastric adenocarcinoma. Am J Pathol. 1992; 140:769-74.

4. Szkaradkiewicz A, Majewski W, Wal M, et al. Epstein-Barr virus (EBV) infection and $\mathrm{p} 53$ protein expression in gastric carcinoma. Virus Res. 2006; 118:115-9.

5. Durmaz R, Aydin A, Koroglu M, et al. Investigation of the relationship between Epstein-Barr virus and ordinary gastric carcinoma using the nested polymerase chain reaction. Acta Virol. 1998; 42:359-63.

6. Murphy G, Pfeiffer R, Camargo MC, et al. Meta-analysis shows that prevalence of Epstein-Barr virus-positive gastric cancer differs based on sex and anatomic location. Gastroenterology. 2009; 137:824-33.

7. Gulley ML, Tang W. Laboratory assays for Epstein-Barr virusrelated disease. J Mol Diagn. 2008; 10:279-92.

8. Ryan JL, Fan H, Glaser SL, et al. Epstein-Barr virus quantitation by real-time PCR targeting multiple gene segments: a novel approach to screen for the virus in paraffin-embedded tissue and plasma. J Mol Diagn. 2004; 6:378-85.
9. Wu MS, Shun CT, Wu CC, et al. Epstein-Barr virus-associated gastric carcinomas: relation to $H$. pylori infection and genetic alterations. Gastroenterology. 2000; 118:1031-8.

10. Saxena A, Nath Prasad K, Chand Ghoshal U, et al. Association of Helicobacter pylori and Epstein-Barr virus with gastric cancer and peptic ulcer disease. Scand J Gastroenterol. 2008; 43:669-74.

11. Ryan JL, Morgan DR, Dominguez RL, et al. High levels of Epstein-Barr virus DNA in latently infected gastric adenocarcinoma. Lab Invest. 2009; 89:80-90.

12. Hirano A, Yanai H, Shimizu N, et al. Evaluation of EpsteinBarr virus DNA load in gastric mucosa with chronic atrophic gastritis using a real-time quantitative PCR assay. Int J Gastrointest Cancer. 2003; 34:87-94.

13. Kaizaki Y, Sakurai S, Chong JM, et al. Atrophic gastritis, Epstein-Barr virus infection, and Epstein-Barr virus-associated gastric carcinoma. Gastric Cancer. 1999; 2:101-8.

14. Yanai H, Takada K, Shimizu N, et al. Epstein-Barr virus infection in non-carcinomatous gastric epithelium. J Pathol. 1997; 183:293-8.

15. Young LS, Rickinson AB. Epstein-Barr virus: 40 years on. Nat Rev Cancer. 2004; 4:757-68.

16. Minoura-Etoh J, Gotoh K, Sato R, et al. Helicobacter pyloriassociated oxidant monochloramine induces reactivation of Epstein-Barr virus (EBV) in gastric epithelial cells latently infected with EBV. J Med Microbiol. 2006; 55:905-11.

17. Singh M, Prasad KN, Yachha SK, et al. Genotypes of Helicobacter pylori in children with upper abdominal pain. J Gastroenterol Hepatol. 2003; 18:1018-23.

18. Schabereiter-Gurtner C, Hirschl AM, Dragosics B, et al. Novel real-time PCR assay for detection of Helicobacter pylori infection and simultaneous clarithromycin susceptibility testing of stool and biopsy specimens. J Clin Microbiol. 2004; 42:4512-8.

19. Lauren P. the two histological main types of gastric carcinoma: diffuse and so-called intestinal-type carcinoma. An attempt at a histo-clinical classification. Acta Pathol Microbiol Scand. 1965; 64:31-49.

20. Luo B, Wang Y, Wang XF, et al. Expression of Epstein-Barr virus genes in EBV-associated gastric carcinomas. World J Gastroenterol. 2005; 11:629-33.

21. Chen PC, Pan CC, Yang AH, et al. Detection of Epstein-Barr virus genome within thymic epithelial tumours in Taiwanese patients by nested PCR, PCR in situ hybridization, and RNA in situ hybridization. J Pathol. 2002; 197:684-8.

22. Gan YJ, Razzouk BI, Su T, et al. A defective, rearranged Epstein-Barr virus genome in EBER-negative and EBER-positive Hodgkins disease. Am J Pathol. 2002; 160:781-6.

23. Korabecna M, Ludvikova M, Skalova A. Molecular diagnosis of Epstein-Barr virus in paraffin-embedded tissues of tumors with abundant lymphoid infiltration. Neoplasma. 2003; 50:8-12.

24. Ryan JL, Jones RJ, Elmore SH, et al. Epstein-Barr virus WZhet DNA can induce lytic replication in epithelial cells in vitro, although WZhet is not detectable in many human tissues in vivo. Intervirology. 2009; 52:8-16.

25. Hsieh LL, Lin PJ, Chen TC, et al. Frequency of Epstein-Barr virus-associated gastric adenocarcinoma in Taiwan. Cancer Lett. 1998; 129:125-9.

26. Alipov G, Nakayama T, Nakashima M, et al. Epstein-Barr virus-associated gastric carcinoma in Kazakhstan. World J Gastroenterol. 2005;11:27-30.

27. Lima VP, de Lima MA, Andre AR, et al. H. pylori (CagA) and Epstein-Barr virus infection in gastric carcinomas: correlation with p53 mutation and $\mathrm{c}-\mathrm{Myc}, \mathrm{Bcl}-2$ and Bax expression. World J Gastroenterol. 2008; 14:884-91. 
28. Rugge M, Genta RM. Epstein-Barr virus: a possible accomplice in gastric oncogenesis. J Clin Gastroenterol. 1999; 29:3-5.

29. Saxena A, Prasad KN, Ghoshal UC, et al. Polymorphism of $-765 \mathrm{G}>\mathrm{C}$ COX-2 is a risk factor for gastric adenocarcinoma and peptic ulcer disease in addition to $\mathrm{H}$ pylori infection: a study from northern India. World J Gastroenterol. 2008; 14:1498-503.

30. Sipponen P, Kosunen TU, Valle J, et al. Helicobacter pylori infection and chronic gastritis in gastric cancer. J Clin Pathol. 1992; 45:319-23.

31. Craanen ME, Blok P, Dekker W, et al. Helicobacter pylori and early gastric cancer. Gut. 1994; 35:1372-4.

32. Tang YL, Gan RL, Dong BH, et al. Detection and location of Helicobacter pylori in human gastric carcinomas. World J Gastroenterol. 2005; 11:1387-91.

33. Zhang C, Yamada N, Wu YL, et al. Helicobacter pylori infection, glandular atrophy and intestinal metaplasia in superficial gastritis, gastric erosion, erosive gastritis, gastric ulcer and early gastric cancer. World J Gastroenterol. 2005; 11:791-6.
34. Kate V, Ananthakrishnan N. Helicobacter pylori and gastric carcinoma: evidence for the link. Natl Med J India. 2000; 13:329.

35. Khanna AK, Seth P, Nath G, Dixit VK, et al. Correlation of Helicobacter pylori and gastric carcinoma. J Postgrad Med. 2002; 48:27-8.

36. Sivaprakash R, Rao UA, Thyagarajan SP, et al. Investigation for the prevalence of Helicobacter pylori infection in patients with gastric carcinoma in Madras, India. Jpn J Med Sci Biol. 1996; 49:49-56.

37. Konturek PC, Kania J, Konturek JW, et al. H. pylori infection, atrophic gastritis, cytokines, gastrin, COX-2, PPAR gamma and impaired apoptosis in gastric carcinogenesis. Med Sci Monit. 2003; 9: 53-66.

38. Semino-Mora C, Doi SQ, Marty A, et al. Intracellular and interstitial expression of Helicobacter pylori virulence genes in gastric precancerous intestinal metaplasia and adenocarcinoma. J Infect Dis. 2003; 187:1165-77. 